\title{
Superposition method for multi rows of a film cooling hole on a turbine stationary vane surface
}

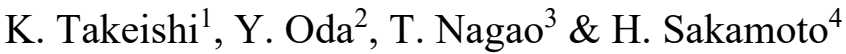 \\ ${ }^{1}$ Tokushima Bunri University, Japan \\ ${ }^{2}$ Kansai University, Japan \\ ${ }^{3}$ Mitsubishi Heavy Industries Ltd., Komaki, Japan \\ ${ }^{4}$ IHI Corporation, Yokohama, Japan
}

\begin{abstract}
The superposition characteristics of film cooling effectiveness in the multi rows of shaped film cooling holes are investigated experimentally. It appeared from the experiments that the superposition characteristics are realized at a small blowing ratio of $M=0.5$. However, the film cooling effectiveness that is estimated by a method presented by Seller is approximately $20 \%$ higher values than that of the experimental value at blowing ratio of $M=1.0$. And furthermore, it becomes clear that the estimated film cooling effectiveness is approximately $100 \%$ higher than that of the experiment at $M=2.0$. On the other hand, by the experiment using a lowspeed cascade test facility, it becomes clear that the superposition of the film cooling effectiveness blowing through two rows of shaped film cooling hole is established on the pressure surface of a stationary turbine vane because of a strong mixing motion of film cooling air and main stream. On the contrary, it became clear that the estimated value showed approximately 30\% lower value compared with the experimental value on the suction surface of the model turbine vane. Keywords: gas turbine, film cooling, superposition method, PSP, LIF.
\end{abstract}

\section{Introduction}

Modern high-temperature industrial gas turbines applied to the gas turbine combined cycle (GTCC) play a significant role against global warming in electric power generation. Currently, $1600^{\circ} \mathrm{C}$-class gas turbines are being operated 
commercially worldwide with considerable success [1]. Moreover, there is high demand for improving the thermal efficiency of gas turbines, and the target thermal efficiency of near-future GTCC is $64 \%$ for $1700^{\circ} \mathrm{C}$-class gas turbines [2].

With an increase in the turbine inlet temperature, the turbine vanes and blades are exposed to a high-temperature gas stream and subjected to a severe thermal environment. The first stationary vanes are subjected to such severe thermal conditions and need an elaborate cooling system. In such hightemperature gas turbines, the surfaces of the blades and vanes must be cooled externally by full coverage film cooling. This is achieved by injecting relatively cooler air from the multi rows of film cooling holes out of the blade surface for forming a protective cooling layer between the surface and the path of hot gas flow. When the full coverage film cooling, which is built with multi rows of film cooling holes, generally a so-called Seller's method to estimate the film cooling effectiveness of the next row of film cooling, which gushed that a film cooling air of the previous row of film cooling acts like as the mainstream of the next film cooling. It is very important to understand whether this Seller's method can be applied or not for the design of full-coverage film cooling of the turbine blades and vanes.

As a fundamental study, we examine the additive nature of film cooling, blowing through rows of shaped film cooling holes on the flat plate by using low speed wind tunnel, and on the vane pressure surface (PS) and suction surface (SS) of the enlarged $\mathrm{E}^{3}$ turbine vane by using low speed cascade test facility, and compare the measured film cooling effectiveness with the one predicted by the superposition method.

\section{Superposition of film cooling}

The superposition method of the film cooling flow is an idea to estimate film cooling effectiveness of the second row of film cooling holes, which are located downstream the first row of holes. Film cooling effectiveness of the second row of holes must be affected by the upstream film coolant jet. In this method, the mixture of the film cooling jet from the upstream (or first) hole and mainstream is assumed to play the role of the "mainstream" in the downstream film cooling from the second hole. This concept of the superposition method for multi rows of film cooling holes was proposed by Seller [3]. The film cooling effectiveness by the first cooling hole, which is located at $s=0$, is defined by the following equation

$$
\eta_{1}^{\prime}=\frac{T_{\infty}-T_{\mathrm{f} 1}}{T_{\infty}-T_{c}}
$$

Note that $T_{\mathrm{f} 1}$ is given by the data of a single row of holes case. When the superposition method of the film cooling is applied, the film cooling effectiveness by the second cooling hole, which is located at $s=L$, can be defined by the following equation 


$$
\eta_{2}^{\prime}=\frac{T_{\mathrm{f} 1}-T_{\mathrm{f} 2}}{T_{\mathrm{f} 1}-T_{\mathrm{c}}}
$$

Here, it is assumed that $T_{\mathrm{fl}}$ acts as a mainstream temperature for the second film hole. Then we can predict the film cooling effectiveness downstream the second hole when film cooling jets blow through two in-line cooling holes simultaneously, by the following equation using $\eta_{1}$ ' and $\eta_{2}$ ' obtained in a single row of holes case

$$
\eta_{2}=\frac{T_{\infty}-T_{\mathrm{f} 2}}{T_{\infty}-T_{\mathrm{c}}}=\eta_{1}^{\prime}+\eta_{2}^{\prime}\left(1-\eta_{1}^{\prime}\right)
$$

The well-known blowing ratio $M$ is defined by the following equation

$$
M=\frac{\rho_{c} u_{c}}{\rho_{\infty} u_{\infty}}
$$

\section{Experimental apparatus and methods}

\subsection{Experimental apparatus}

The experiments have been conducted by using a flat plate model installed in a low speed wind tunnel and a low speed cascade test facility with an enlarged first stage model of an Energy Efficient Engine ( $\left.\mathrm{E}^{3}\right)$ turbine [5]. Figure 1 and Table 1 show the geometry of the shaped film cooling hole, and the layout of the two rows of film cooling holes respectively. The geometry and dimensions of the low speed cascade is shown in Figure 2 and the geometry and the locations of the static pressure taps [6] on the model turbine vane are shown in Figure 3 respectively. The static pressure distributions measured by static pressure taps on the model vane surface are shown in Figure 4.

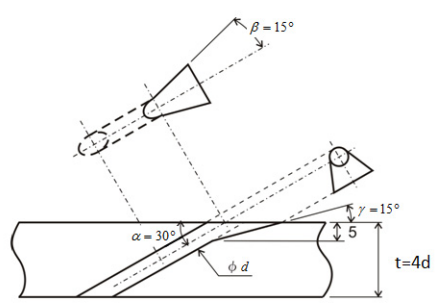

(a) Geometry

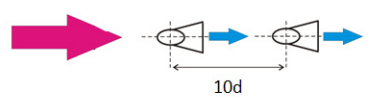

(b) Layout

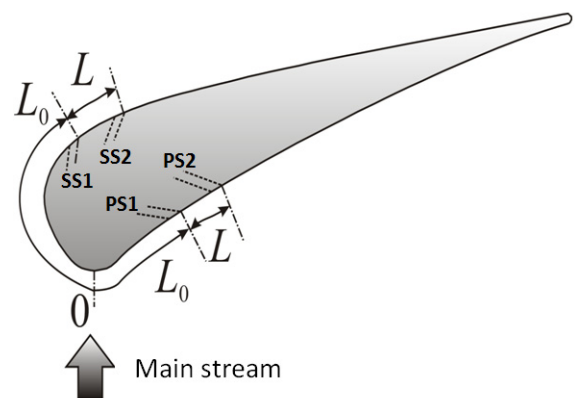

(c) Layout on the model vane

Figure 1: Geometry and layout of film cooling holes. 
Table 1: Location of film cooling holes on a model vane.

\begin{tabular}{|c|c|c|c|c|}
\hline \multirow[b]{2}{*}{ Film cooling hole location } & \multicolumn{2}{|c|}{ Pressure surface } & \multicolumn{2}{|c|}{ Suction surface } \\
\hline & 1st & 2nd & 1st & 2nd \\
\hline Cooling hole diameter $d[\mathrm{~mm}]$ & \multicolumn{4}{|c|}{2.5} \\
\hline Injection angle $\alpha$ [degree] & \multicolumn{2}{|c|}{30} & 40 & 30 \\
\hline$\beta[$ degree $]$ & \multicolumn{4}{|c|}{15} \\
\hline$\gamma[$ degree $]$ & \multicolumn{2}{|c|}{15} & 20 & 15 \\
\hline $\begin{array}{c}\text { Distance from stagnation } \\
\text { point. } L_{0}[\mathrm{~mm}]\end{array}$ & \multicolumn{2}{|c|}{56} & \multicolumn{2}{|c|}{46} \\
\hline Distance $L[\mathrm{~mm}]$ & \multicolumn{2}{|c|}{25} & \multicolumn{2}{|c|}{25} \\
\hline $\begin{array}{l}\text { Non-dimensional distance. } \\
L_{0} / S^{\star}\end{array}$ & 0.20 & 0.29 & 0.20 & 0.31 \\
\hline Location $x / C_{a x}$ & 0.24 & 0.37 & 0.46 & 0.59 \\
\hline
\end{tabular}

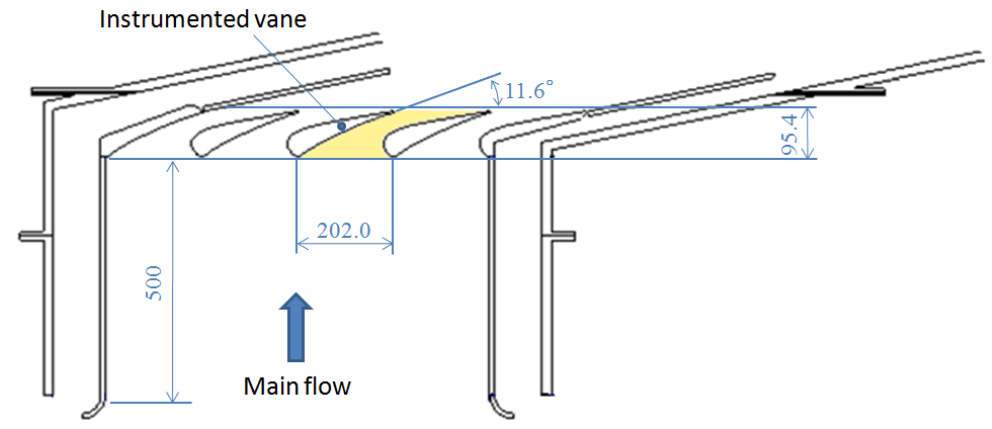

Figure 2: Layout of low speed cascade test facility.

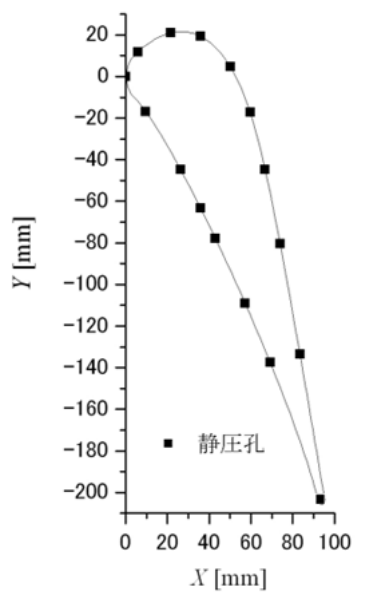

\begin{tabular}{|c|c|}
\hline Scale & 2.19 \\
\hline Number of Airfoil & 5 \\
\hline Axial Chord $\mathrm{C}_{\mathrm{ax}}[\mathrm{mm}]$ & 95.4 \\
\hline Chord C [mm] & 224.6 \\
\hline Span S [mm] & 150.0 \\
\hline Pitch P [mm] & 202.0 \\
\hline L.E. Diameter [mm] & 29.2 \\
\hline T.E. diameter [mm] & 3.6 \\
\hline Inlet Foil Angle [ $\left.{ }^{\circ}\right]$ & 90.0 \\
\hline Exit Foil Angle [ $\left.{ }^{\circ}\right]$ & 11.6 \\
\hline
\end{tabular}

Figure 3: Airfoil profile, location of static taps and cascade parameters. 


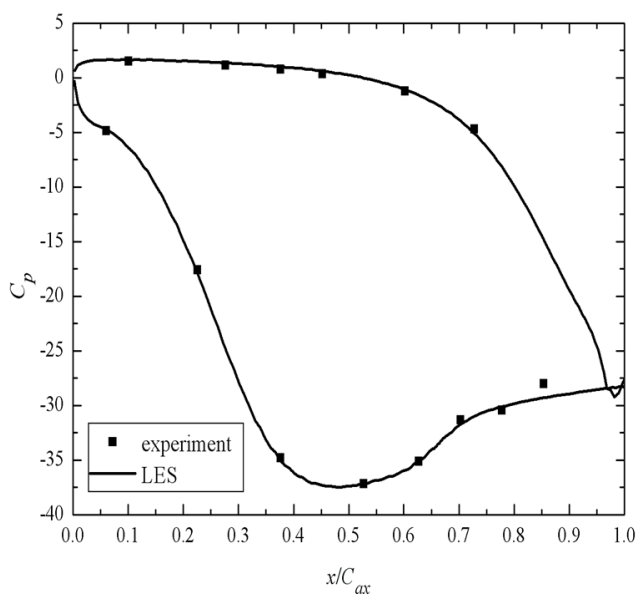

Figure 4: Static pressure distribution around the model vane.

\subsection{PSP method}

In this study, pressure sensitive paint (PSP) was used to measure film cooling effectiveness distribution on the surface. The PSP is an optical pressure sensor. It uses a special pigment that changes its luminescence intensity reacting with oxygen molecules. The change of luminescence intensity is caused by optical quenching of the pigment by oxygen molecules. Therefore, we can measure a change of the concentration of oxygen by the luminescence intensity of the pigment. By using air (concentration of oxygen is $21 \%$ ) for mainstream and nitrogen (concentration of oxygen is $0 \%$ ) for film cooling jets, the concentration distribution of oxygen that changes by those mixing is measured by PSP. Then, using an analogy between heat/mass transfers, Eq. (1) can be converted to Eq. (5) using the mass concentration of oxygen, $C$.

$$
\eta=\frac{C_{\infty}-C}{C_{\infty}-C_{c}}
$$

Schematic view of the experimental apparatus of PSP is shown in Figure 5. Since PSP's luminescence intensity varies with its temperature, we have calibrated it by investigating its dependency on temperature in advance, and temperature of the PSP painted wall was monitored by a K-type thermocouple during experiments.

\subsection{Acetone LIF method}

Laser induced fluorescence (LIF) is a measurement method for mass concentration in a gaseous flow. LIF has the advantages of being non-intrusive, instantaneous, and having a high intensity of fluorescence. In addition, LIF can realize high spatial resolution for a tracer concentration field. The flow is illuminated by a laser sheet, whose wavelength is tuned to excite a specific absorption transition of a molecular tracer that is added for this purpose. A fraction of the molecules in the 


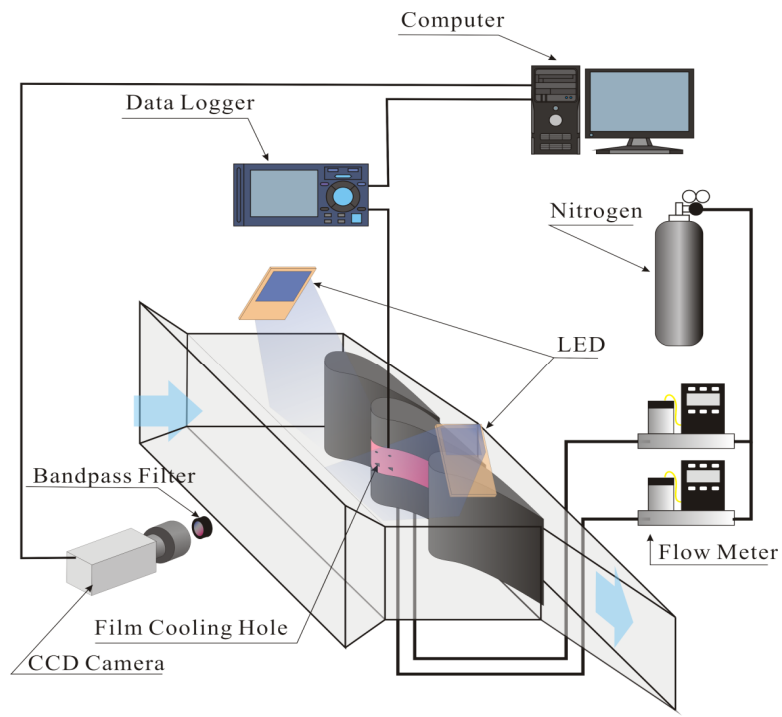

Figure 5: Schematic layout of PSP method to measure film cooling effectiveness on the model vane.

lower energy levels absorbs the incident light and are excited to a higher energy state. When the excited state returns to the state with lower energy, fluorescent light is emitted at a different wavelength and is easily extracted from the scattered light using an interference filter. If the thermal diffusivity of the air and the mass diffusivity of the tracer are close, then the mass transfer can replace the thermal diffusion based on the analogy between heat and mass transfer. Thus, just as with the PSP, the local non-dimensional concentration or non-dimensional temperature, $\theta$, can be obtained by Eq. (6)

$$
\theta=\frac{T_{\infty}-T}{T_{\infty}-T_{c}}=\frac{C_{\infty}-C}{C_{\infty}-C_{c}}
$$

where $\mathrm{C}_{\infty}$ : Mainstream tracer concentration, $\mathrm{C}_{\mathrm{c}}$ : Coolant tracer concentration at the cooling holes exit and $\mathrm{C}$ : Tracer concentration in the mixing field.

Lozano et al. [7] showed that acetone is a suitable tracer for concentration measurements in gaseous flows with LIF. The detail application of the acetone LIF is described in reference [8].

\section{Results and discussion}

\subsection{Film cooling effectiveness on a flat plate}

Figures 6 and 7 show the film cooling effectiveness measured by PSP of a single hole and two in-line holes on a flat plate, respectively. It can be confirmed from single hole case that film coolant is always attached to the wall for all blowing 
ratios. Thus, the film coolant from a shaped hole is attached over a longer distance downstream as the blowing ratio increases. In addition, it is also confirmed from the cases of two in-line shaped holes that the shapes of film effectiveness distribution around the first and second holes are similar, and it seems to be independent. This implies that film cooling flows from the second hole are not drastically affected by the upstream film cooling flows as to change the shape of its film effectiveness distributions. Therefore, it can be expected that the abovementioned superposition method can hold for the two in-line shaped cooling holes.

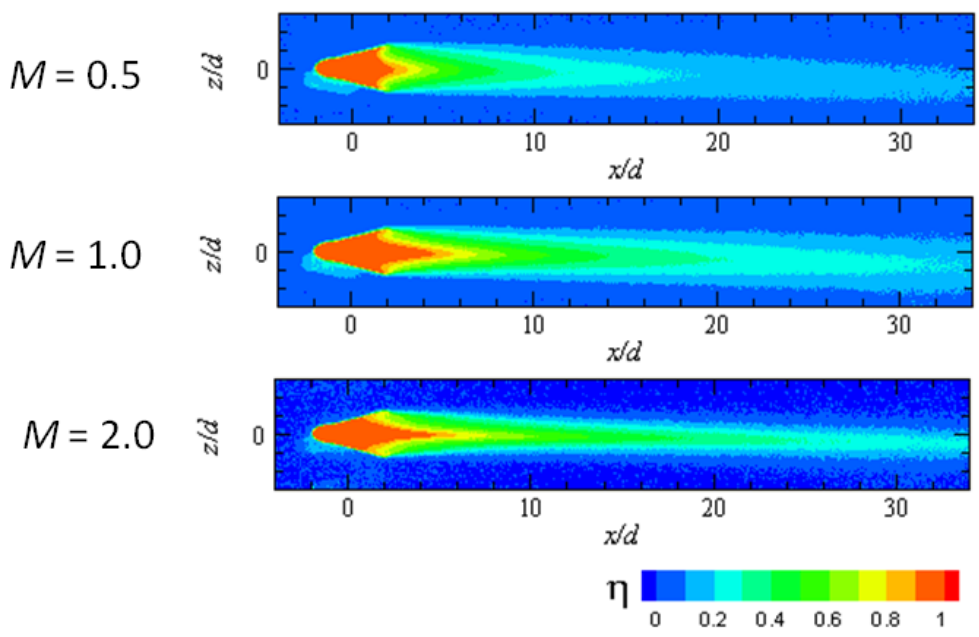

Figure 6: Film cooling effectiveness of a single film cooling hole.

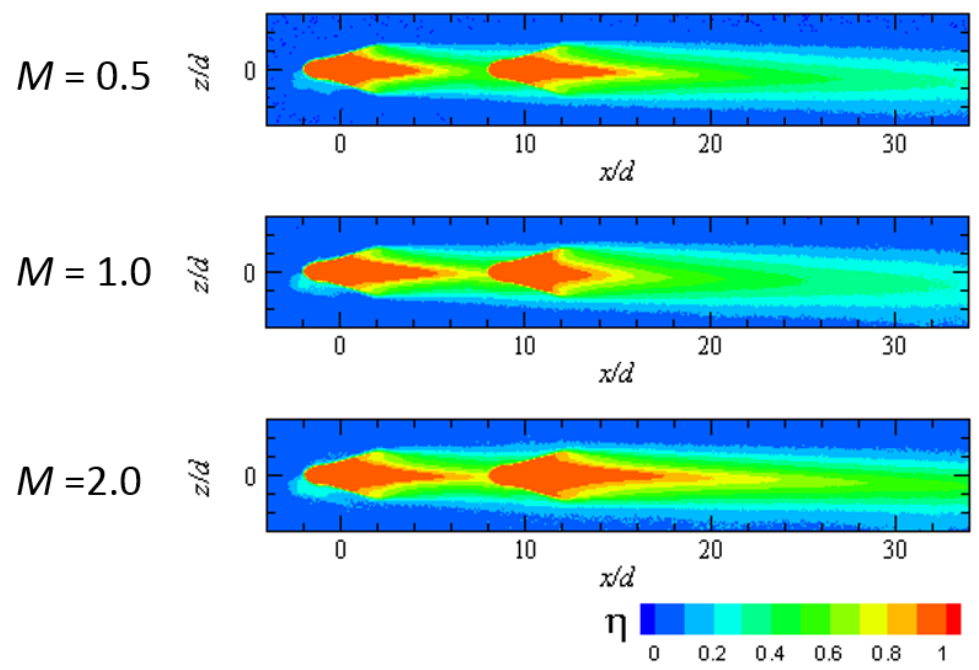

Figure 7: Film cooling effectiveness of two rows film cooling hole. 
The lateral average of local effectiveness over $-3<z / d<3$ at each $x$ position for blowing ratios $M=0.5$ to 2.0 of the measured film cooling effectiveness by PSP is compared with the values predicted by the superposition method using Eq. (3). Figure 8(a) to (c) show measured and predicted values of lateral averaged film cooling effectiveness for $M=0.5,1.0$ and 2.0 respectively. Note that the
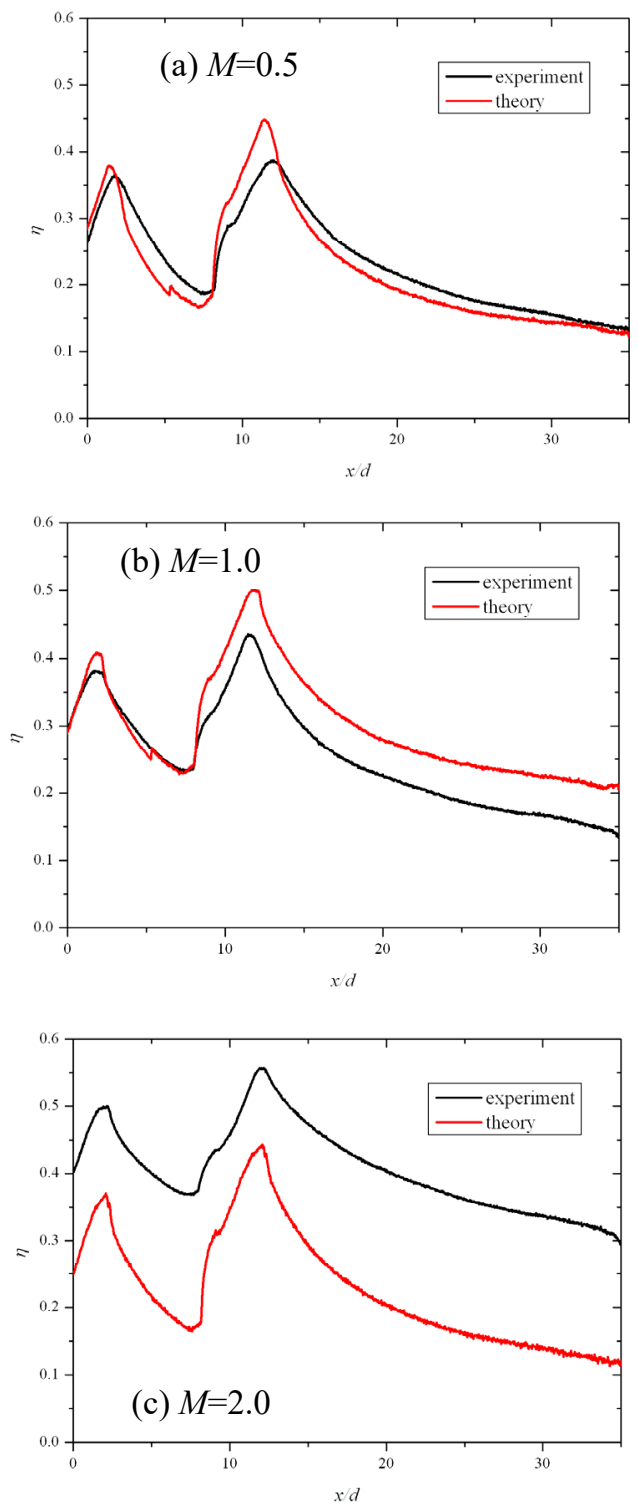

Figure 8: Comparison of averaged film cooling effectiveness between measured one and estimated from superposition method. 
superposition method uses experimental results of a single row of holes case to predict the film cooling effectiveness downstream the first and second film cooling holes of the two in-line holes.

These figures show that the additive nature of film cooling effectiveness acts well when blowing ratio $M$ is low, but shows some deviation from measured value at high blowing ratios, especially at $M=2.0$. This seems to be because film cooling flows from the first hole is affected by the film cooling jet from the second hole at $M=2.0$ due to the large mass flow rate. This is indicated by the large difference between experimental and predicted values upstream the second hole, which implies that penetration of the film cooling jet into mainstream is suppressed by the blockage effect of the second cooling jet. Predicted values in two in-line holes were calculated using the data of a single hole case, where film coolant usually penetrates into the mainstream at $M=2.0$. Thus, the present superposition method cannot consider the blockage effect of the second cooling jets, which actually suppresses the detachment of the film cooling jet due to the jet penetration in two in-line holes' cases.
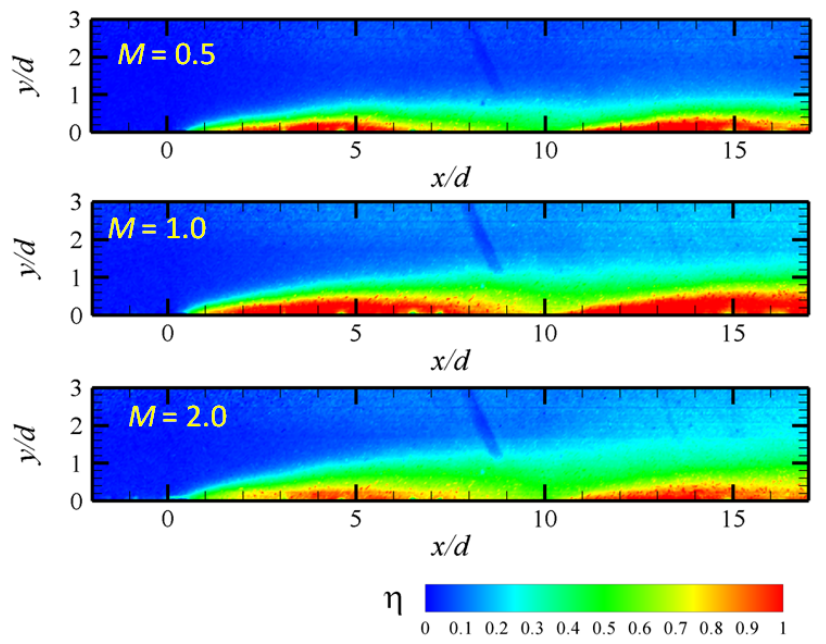

Figure 9: Mixing field of film cooling blowing through two rows of film cooling hole measured by acetone LIF.

\subsection{Film cooling effectiveness on pressure surface of a model turbine vane}

Figures 10 and 11 show the film cooling effectiveness measured by PSP of a single hole and two in-line holes on pressure surface of the model vane, respectively. It can be confirmed from these figures that the film jet from a shaped cooling hole spreads wider both in a lateral and mainstream directions and the penetration of film coolant into the mainstream was suppressed in the shaped hole at lower blowing ratio $M$ less than 1.5 , however penetration of film coolant occurs at high blowing ratio of $M=2.0$. 

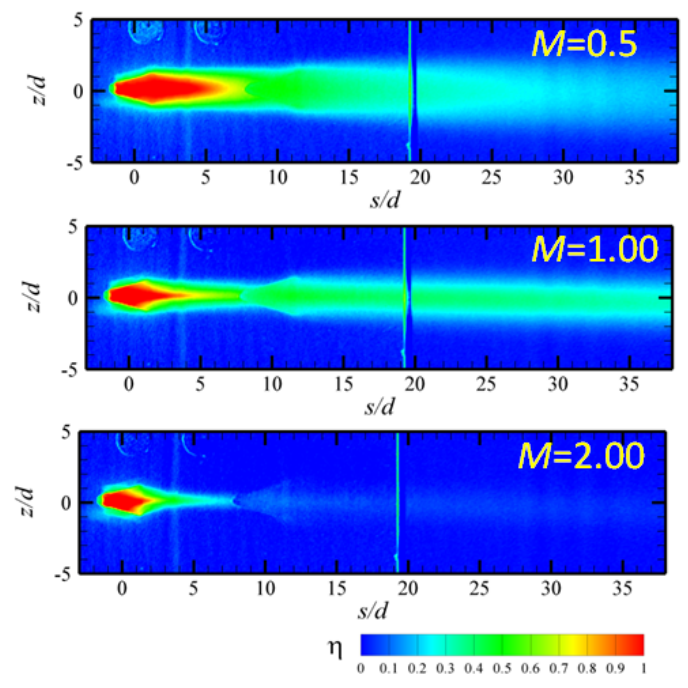

Figure 10: Film cooling effectiveness blowing through PS1 (pressure surface).
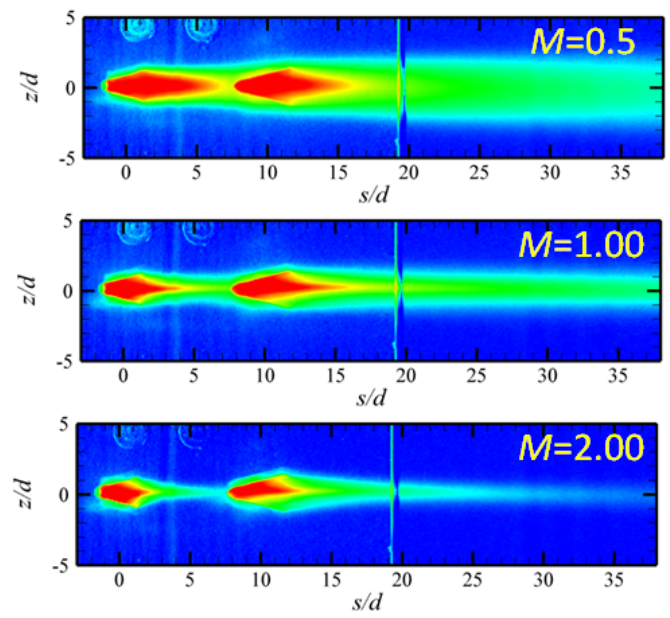

$\eta$

\begin{tabular}{lllllllllll}
\hline 0 & 0.1 & 0.2 & 0.3 & 0.4 & 0.5 & 0.6 & 0.7 & 0.8 & 0.9 & 1
\end{tabular}

Figure 11: Film cooling effectiveness blowing through PS1 and PS2.

Figure 12 shows the comparison between measured and predicted values of lateral averaged film cooling effectiveness for $M=1.0$. If the film cooling air does not penetrate into the mainstream, the film cooling air is mixed with the mainstream on the concave surface of the model vane and the measured film cooling effectiveness agrees well with a predicted value on the pressure surface of the model turbine. Figure 13 shows the concentration distribution of acetone on pressure surface of the model vane measured by acetone LIF and it is clear that 
strong mixing occurs between the coolant from the first film hole and that from the second film hole and the mainstream from this figure.

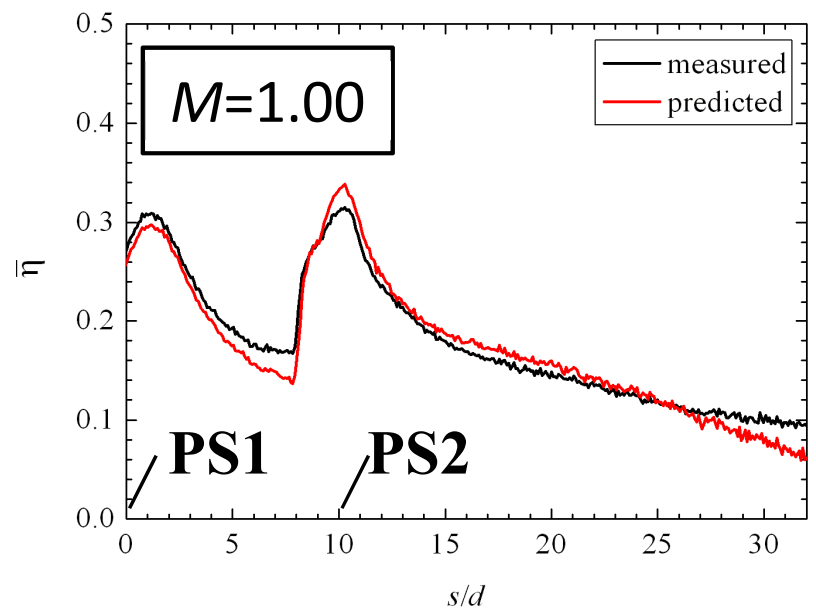

Figure 12: Comparison of averaged film cooling effectiveness of PS1 and PS2 between measured one and estimated from superposition method.

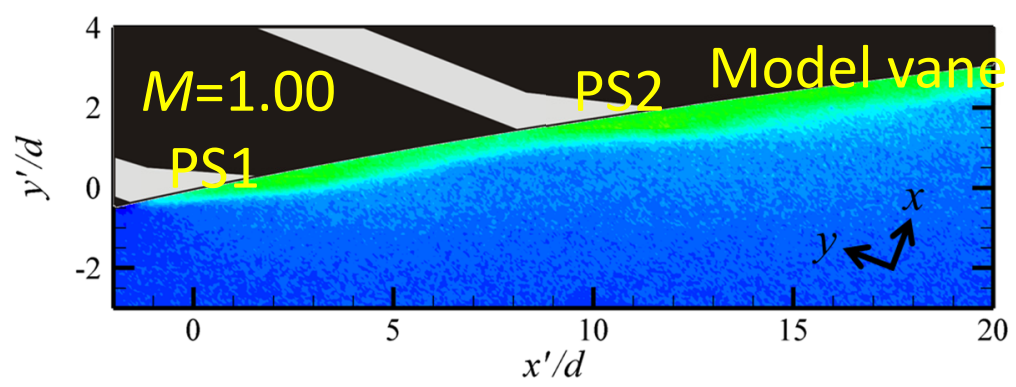

Figure 13: Mixing field of film cooling blowing through PS1 and PS2 measured by acetone LIF.

\subsection{Film cooling effectiveness on suction surface of a model turbine vane}

Figures 14 and 15 show the film cooling effectiveness measured by PSP of a single shaped hole and two in-line shaped holes on the suction surface of the model vane, respectively. Comparison between Figures 10 and 11 and Figures 14 and 15 shows that the film cooling effectiveness of a single shaped hole and two in-line shaped holes, at $M=1.0$ is higher on the suction surface than on the pressure surface. The film cooling air has a tendency apart from the wall on the pressure surface of the vane and the mixing between film cooling air and mainstream is easily occurred on the concave surface. On the other hand, there is a tendency that the film cooling air adheres on the wall of suction surface and film cooling air and the mainstream is hard to mix on the suction surface of the model vane. 

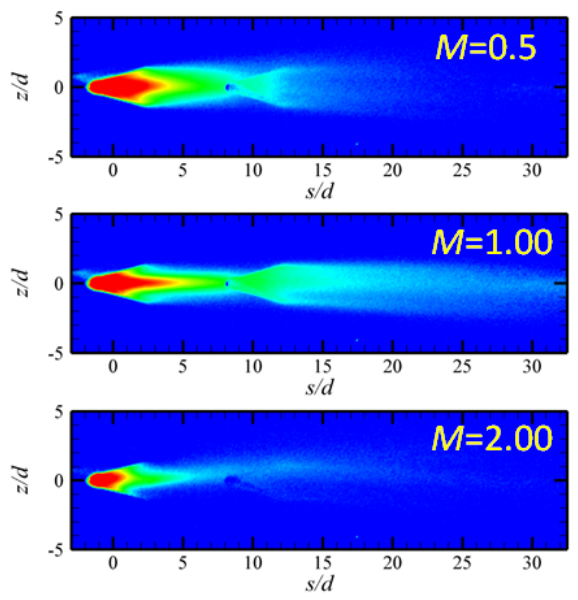

$\eta$

$\begin{array}{lllllllllll}0 & 0.1 & 0.2 & 0.3 & 0.4 & 0.5 & 0.6 & 0.7 & 0.8 & 0.9 & 1\end{array}$

Figure 14: Film cooling effectiveness blowing through SS1 (suction surface).
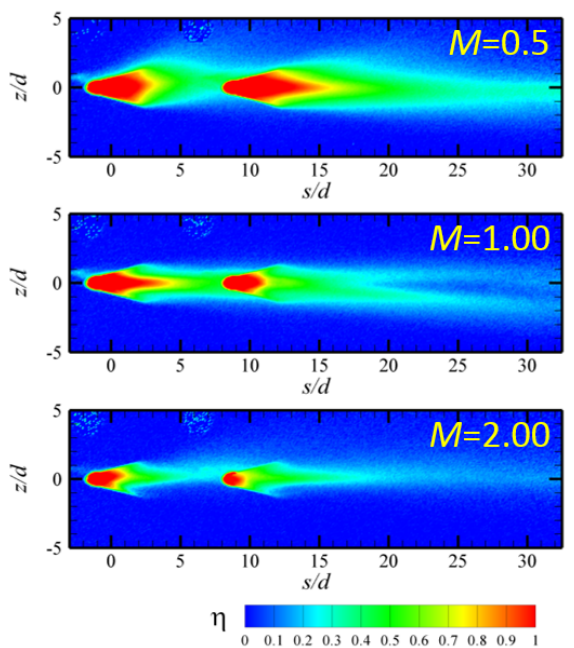

Figure 15: Film cooling effectiveness blowing through SS1 and SS2.

Figure 16 shows the comparison between measured and predicted values of lateral averaged film cooling effectiveness for $M=1.0$ on the suction surface of the model vane. The predicted value is about 30\% higher than that of the measured one. The reason why lower precision of the prediction of the film cooling effectiveness by the superposition method is weak mixing of the film cooling air on the suction surface of the model vane. Figure 17 shows the concentration distribution of acetone on the suction surface of the model vane measured by acetone LIF and it is clear from this figure that the film cooling air blowing from 
the first shaped hole covers over the film cooling air blowing from the second shaped film cooling air.

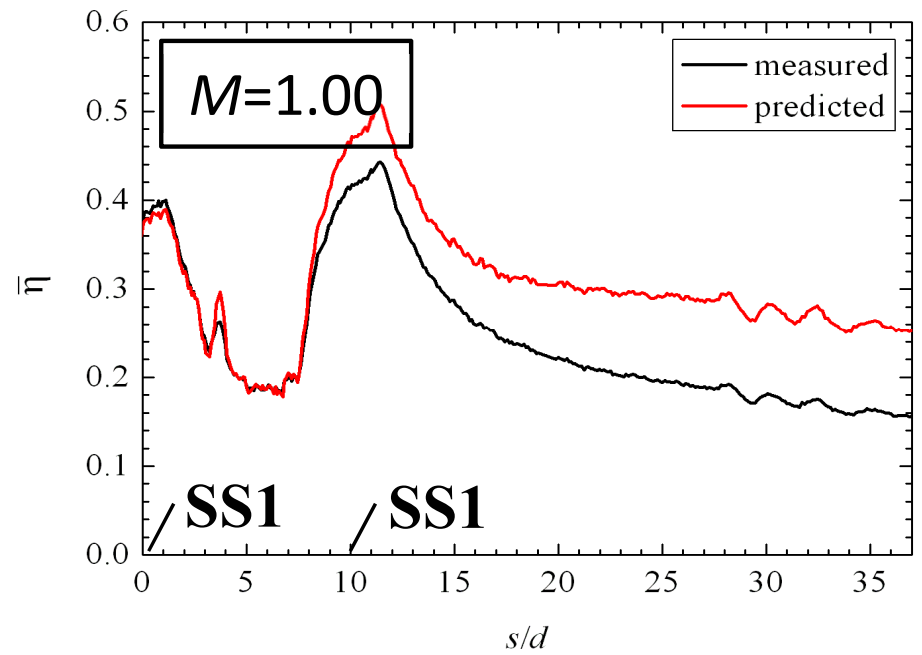

Figure 16: Comparison of averaged film cooling effectiveness of SS1 and SS2 between measured one and estimated from superposition method.

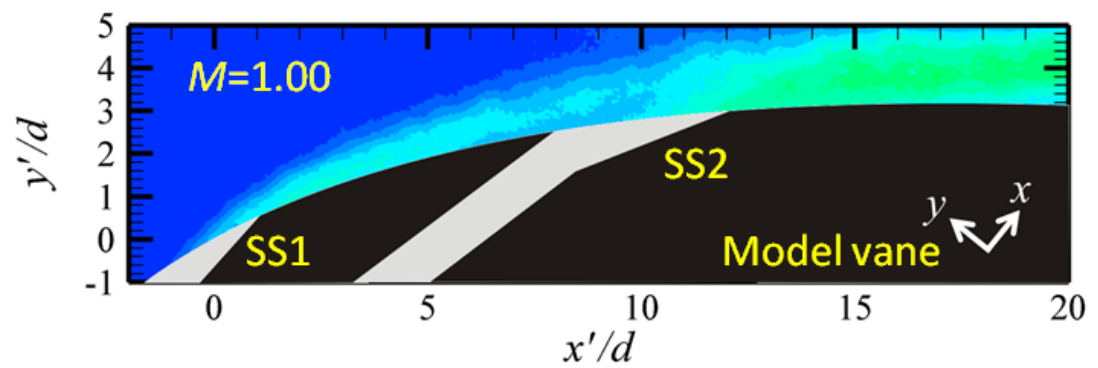

Figure 17: Mixing field of film cooling blowing through SS1 and SS2 measured by acetone LIF.

The property of the mixing phenomena on the convex surface of the vane contributes to attaining higher film cooling effectiveness on the suction surface of the vane, however, it becomes a cause to lay disagreement between a predicted value and experimentally measured values because the supposition method built based on the mixing of film cooling air will fail to predict on the suction surface.

\section{Conclusions}

In this study, the superposition method of shaped film cooling holes in a turbine vane surface is examined by the comparison between experimental data of PSP technique and predicted values by a superposition method. As a result, the following conclusions are obtained. 
1. The measured film cooling effectiveness and the predicted one by the superposition method show that the additive nature of film cooling acts well when blowing ratio $M$ is less than 1.5 , but does not agree well when blowing ratio $M=2.0$.

2. The measured film cooling effectiveness and predicted one show good agreement on the pressure surface of the model vane.

3. The superposition method estimates about $30 \%$ higher film cooling effectiveness than the measured one at $M=1.0$ on the suction surface of the model vane. The more appropriate mixing model should be established to improve the estimation of the film cooling effectiveness on the suction surface.

4. The study to investigate the detail mixing phenomena of film cooling on a turbine vane and blade is necessary to improve the accuracy of design tool for full coverage film cooled vanes and blades.

\section{References}

[1] Hada, S., Takata, K., Iwasaki, Y., Yuri, M. and Masada, J., High-efficiency Gas Turbine Development applying $1600^{\circ} \mathrm{C}$ class “J” Technology. Mitsubishi Heavy Industries Technical Review, 52, pp. 2-9, 2015.

[2] Ito, E., Okada, I. Tsukagoshi, K. and Masada, J., Development of key technologies for the next generation high temperature gas turbine. Proceedings of ASME Turbo Expo 2011, Paper No. GT2011-45172, Vancouver, Canada, 2011.

[3] Seller, J.P., Gaseous film cooling with multiple injection stations. AIAA J. Sept., pp. 2154-2156, 1963.

[4] Muska, J.F., Fish, R.W., and Suo, M., The Additive Nature of Film Cooling from Rows of Holes, Trans. ASME Journal of Engineering for Pawor, Vol.98, pp. 457-467, 1976.

[5] Thulin, R.R., Howe, D.C. \& Singer, I.D., Energy efficient engine high performance turbine detailed design report. NASA Report, CR-165608, 1982.

[6] Bunker, R. S., A Review of Shaped Hole Turbine Film Cooling Technology Review, ASME Journal of Heat Transfer, Vol. 127, pp. 441-453, 2005.

[7] Lozano, A., Yip, B. and Hanson, R. K., Acetone: a tracer for concentration measurements in gaseous flows by planar laser-induced fluorescence. Experimental in Fluid, 13, pp. 369-376, 1992.

[8] Takeishi, K, Komiyama, M. and Oda, Y., Quantitative measuring methods applied for the mixing phenomena of film cooling. WIT Transactions on Engineering Sciences, Vol. 83, pp. 491-503, 2014. 